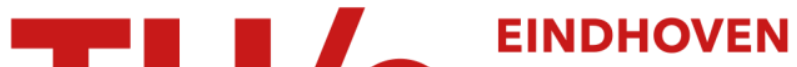 UNIVERSITY OF TECHNOLOGY
}

\section{A numerical method for calculating the output spectrum of an $\mathrm{H}$-bridge inverter with dead-time based on switching mode analysis}

\begin{abstract}
Citation for published version (APA):
Yu, Q., Lemmen, E., \& Vermulst, B. (2019). A numerical method for calculating the output spectrum of an Hbridge inverter with dead-time based on switching mode analysis. In 2019 IEEE Energy Conversion Congress and Exposition (ECCE 2019) (pp. 2245-2251). [8911890] Institute of Electrical and Electronics Engineers. https://doi.org/10.1109/ECCE.2019.8911890
\end{abstract}

DOI:

10.1109/ECCE.2019.8911890

Document status and date:

Published: 01/09/2019

\section{Document Version:}

Accepted manuscript including changes made at the peer-review stage

\section{Please check the document version of this publication:}

- A submitted manuscript is the version of the article upon submission and before peer-review. There can be important differences between the submitted version and the official published version of record. People interested in the research are advised to contact the author for the final version of the publication, or visit the DOI to the publisher's website.

- The final author version and the galley proof are versions of the publication after peer review.

- The final published version features the final layout of the paper including the volume, issue and page numbers.

Link to publication

\footnotetext{
General rights

- You may freely distribute the URL identifying the publication in the public portal. follow below link for the End User Agreement:

www.tue.nl/taverne

\section{Take down policy}

If you believe that this document breaches copyright please contact us at:

openaccess@tue.nl

providing details and we will investigate your claim.
}

Copyright and moral rights for the publications made accessible in the public portal are retained by the authors and/or other copyright owners and it is a condition of accessing publications that users recognise and abide by the legal requirements associated with these rights.

- Users may download and print one copy of any publication from the public portal for the purpose of private study or research.

- You may not further distribute the material or use it for any profit-making activity or commercial gain

If the publication is distributed under the terms of Article $25 \mathrm{fa}$ of the Dutch Copyright Act, indicated by the "Taverne" license above, please 


\title{
A Numerical Method for Calculating the Output Spectrum of an H-Bridge Inverter with Dead-time Based on Switching Mode Analysis
}

\author{
Qihao Yu, Erik Lemmen, Bas Vermulst \\ Electromechanics and Power Electronics, Department of Electrical Engineering \\ Eindhoven University of Technology \\ Eindhoven, the Netherlands \\ q.yu@tue.nl
}

\begin{abstract}
The distortion of an H-bridge inverter originates from many nonlinear factors, of which the most dominant one is typically the dead-time. Different analytical and numerical methods have been proposed to calculate the distortion caused by the dead-time. However, all the existing methods are neglecting the effects of soft-switching and discontinuous conduction mode, resulting in a deviation with the practice. In this paper, the characteristics and the corresponding effects of each individual switching mode is analysed. Current constraint functions are proposed in order to determine the time position of different switching modes. A numerical method for calculating the output spectrum of the H-bridge inverter based on the switching mode analysis is introduced. The method has an improved accuracy compared to the previous analytical method especially when the inductor current ripple is high. The results are verified by simulation and an experimental prototype.
\end{abstract}

Index Terms-harmonics, dead-time, soft-switching, discontinuous conduction mode, hard-switching

\section{INTRODUCTION}

The H-bridge inverter with sine-pulse-width-modulation (SPWM) is widely used in industry. Some applications, such as lithography and magnetic resonance imaging (MRI), demand a high precision and high linearity output [1]. Taking lithography for example, the position error of the moving stage is determined by the non-linearity error of the current amplifier and it requires less than $-100 \mathrm{~dB}$ current distortion for the high-precision motor control [2]. The challenge of the linearity raises the problem of the origin and the magnitude of the inverter distortion.

The nonlinear distortion of the H-bridge inverter originates from different sources, including the SPWM [3], the nonlinear effect of the inductor [4], on-resistance variation of the transistors [5], the dead-time [6], etc. The distortions caused by SPWM with different sampling methods are analysed in [3]. Double Fourier analysis is used to calculate the PWM distortion on the assumption of no dead-time. It is illustrated that low-order harmonic components are produced by PWM thus lowering the output quality. With a high carrier frequency ratio, noise-shaping technique [7] or other compensation methods [8], the low-order harmonic components can be sharply reduced. However, a certain dead-time is required to prevent short circuit in practice, which is typically the most dominant source of distortion [9].

The effect of the dead-time is analysed in [10] and [11]. The switch-node voltage loss during the dead-time when the inductor current is distinctly positive or negative is calculated. The calculated voltage loss accounts for the nonlinear distortion caused by the dead-time. Moreover, several analytical methods for calculating the dead-time distortion have been given in [6], [12] and [13] based on the voltage loss analysis. The analytical results yield monotonically decreasing odd harmonics, which results in a deviation with the practice. In some cases, some lower odd harmonics are smaller than the higher ones, which cannot be explained by the aforementioned analytical methods, as the example that third harmonic smaller than fifth harmonic presented in [1].

The deviation comes from the assumption of distinctly positive or negative inductor current during the dead-time and the resultant voltage loss in the full fundamental period. However, as illustrated in [14], soft-switching is achieved near the zero-crossing region of the inductor current, thus eliminating the switch-node voltage error. Furthermore, the discontinuous conduction mode of the inductor current causes a variable switch-node voltage error, which also contributes to the total dead-time distortion. None of the aforementioned papers has fully investigated all the switching modes and their effects. Therefore, this paper proposes a numerical method for calculating the output spectrum of $\mathrm{H}$-bridge inverter with dead-time by taking different kinds of switching modes into consideration.

The structure of this paper is as follows. The different switching modes, including the soft-switching continuous conduction mode (SSCCM), the discontinuous conduction mode (DCM) and the hard-switching continuous conduction mode (HSCCM), and their corresponding effects are analysed. Then the time position of the different switching modes is determined by a series of current constraint functions. Next, a numerical method is introduced based on the switching mode analysis. Finally, simulations and experiments are conducted to verify the method and conclusions are given. 


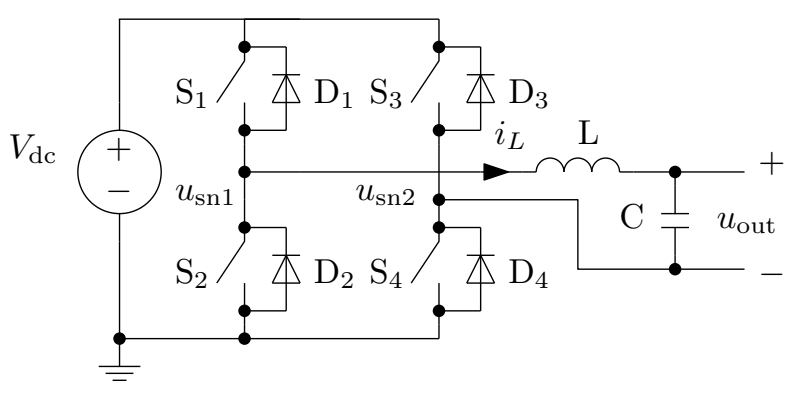

Fig. 1. The H-bridge inverter with output filter.

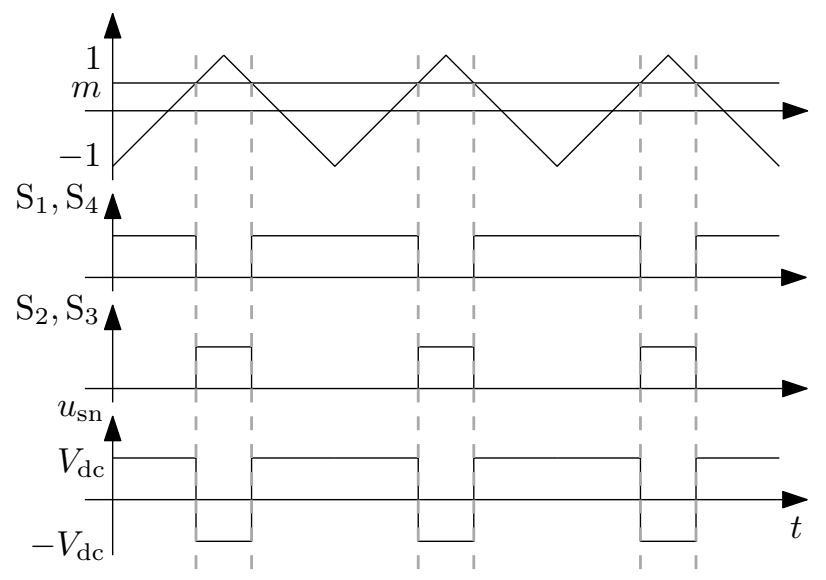

Fig. 2. The ideal PWM waveforms without dead-time. $m$ is the modulation index. The switch is on when the state is high otherwise is off. $u_{\mathrm{sn}}$ is the switch-node voltage and defined by $u_{\mathrm{sn}}=u_{\mathrm{sn} 1}-u_{\mathrm{sn} 2}$.

\section{Output Voltage Spectrum Analysis}

\section{A. H-bridge inverter with SPWM}

The topology of an H-bridge inverter is shown in Fig. 1. In this research, natural sampling SPWM and bipolar modulation are used for an example, as shown in Fig. 2. The rise time and fall time of the switches are assumed to be zero. In another words, the output capacitance of the switches are neglected so the switches can be turned on and off infinitely fast.

During a switching cycle $\left[n T_{\mathrm{sw}},(n+1) T_{\mathrm{sw}}\right]$ with $T_{\mathrm{sw}}$ representing for the switching period and $n$ a non-negative integer, the modulation index for a digital SPWM is defined by

$$
m(n)=M \sin \left(\frac{2 \pi n}{N_{\mathrm{sw}}}\right),
$$

where $M$ is the modulation depth and $N_{\mathrm{sw}}$ is the number of the switching cycles in a full fundamental period, which equals to the ratio of the switching frequency $f_{\mathrm{sw}}$ to the output frequency $f_{\mathrm{o}}$ and is usually larger than 20 . The moving average value of the switch-node voltage is defined by

$$
\left\langle u_{\mathrm{sn}}(n)\right\rangle=V_{\mathrm{dc}} m(n),
$$

where the operator $\langle\cdot\rangle$ gives the average value in a switching cycle. An LC filter is used to reduce the high-frequency distortion and the cut-off frequency $f_{\mathrm{c}}$ is determined by

$$
f_{\mathrm{c}}=\frac{1}{2 \pi \sqrt{L C}}
$$

which is typically chosen at $\frac{1}{5}$ th of the switching frequency $f_{\mathrm{sw}}$ [15]. Therefore, the distortion caused by PWM is regarded as filtered and is neglected in this paper. The output voltage can be regarded as smooth with the output filter and ideally it is equal to the reference voltage and given by

$$
u_{\mathrm{ref}}(t)=M V_{\mathrm{dc}} \sin \left(2 \pi f_{\mathrm{o}} t\right) .
$$

Therefore, the output current is then governed by

$$
i_{\text {out }}(t)=\frac{M V_{\mathrm{dc}}}{Z} \sin \left(2 \pi f_{\mathrm{o}} t-\varphi_{\mathrm{o}}\right),
$$

where $Z$ and $\varphi_{\mathrm{o}}$ are the impedance and phase angle of the load respectively.

\section{B. Switching mode analysis}

In practice, a certain dead-time $T_{\mathrm{d}}$ is required to prevent short circuit, which may result in a voltage error on the switchnode and output, defined by

$$
u_{\mathrm{e}}=u_{\mathrm{ref}}-u_{\mathrm{out}},
$$

where $u_{\text {out }}$ is the output voltage. During the dead-time, both switches on the same leg are off and the switch-node voltage is dependent on the direction of the inductor current. As shown in Fig. 3, the switching cycle can be divided into three modes depending on the inductor current waveform, including SSCCM, DCM and HSCCM.

During the SSCCM cycle, the inductor current is crossing zero and changes the direction alternatively depending on the pair of active switches. As a result, despite the existence of the dead-time, the switch-node voltage $u_{\mathrm{sn}}$ remains the same with the ideal case. Therefore, the voltage error equals to zero. During the DCM cycle, the inductor current rises from negative or falls from positive to zero during the deadtime and then clamped to zero. The switch-node voltage is clamped to the output voltage at the same time. The value of the voltage error is dependent on the current magnitude and phase angle. During the HSCCM cycle, the inductor current is strictly positive or negative, resulting in a fixed voltage error of the same polarity. The effect of the dead-time on the output voltage and current in each of the switching modes is shown in Fig. 4.

During a switching cycle, the average value of filter inductor current is assumed to be the same with the output current and given by

$$
\left\langle i_{L}(n)\right\rangle=\frac{M V_{\mathrm{dc}}}{Z} \sin \left(\frac{2 \pi n}{N_{\mathrm{sw}}}-\varphi_{o}\right) .
$$

The peak-to-average inductor current ripple $\Delta i_{L}(n)$ during an ideal switching cycle is calculated as

$$
\Delta i_{L}(n)=\frac{T_{\mathrm{sw}} V_{\mathrm{dc}}}{4 L}\left[1-m(n)^{2}\right] .
$$




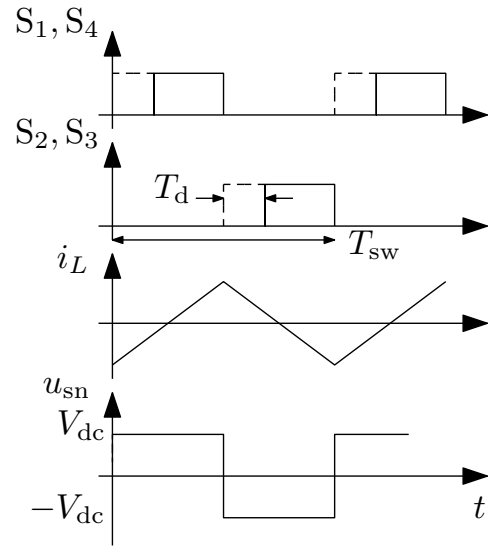

(a)

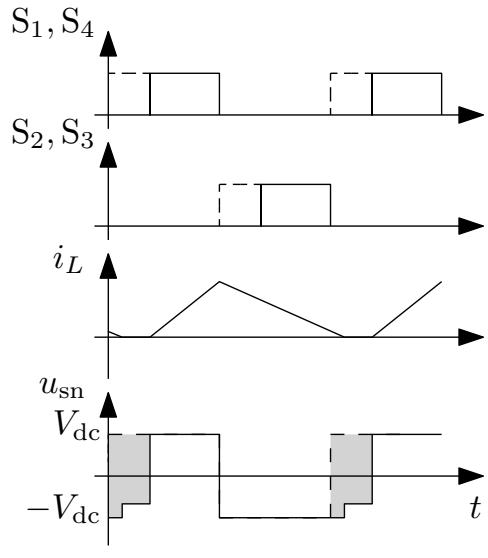

(b)

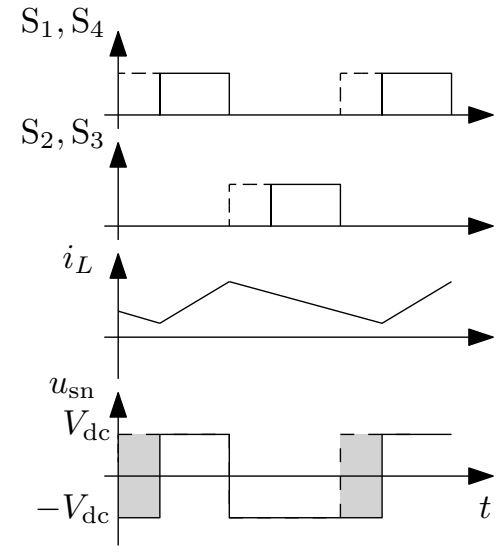

(c)

Fig. 3. Waveforms during a switching cycle. (a) Soft-switching continuous conduction mode. (b) Discontinuous conduction mode. (c) Hard-switching continuous conduction mode. The solid and dashed lines represent the case with and without dead-time respectively. The grey area represents the volt-second error.
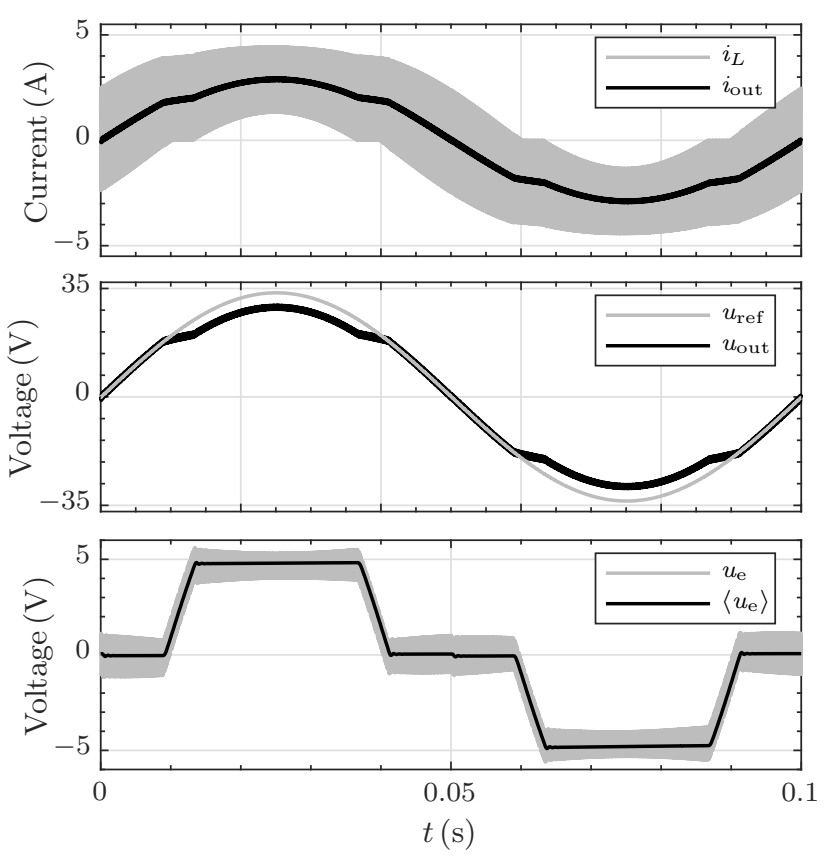

Fig. 4. The simulated waveforms with $V_{\mathrm{dc}}=48 \mathrm{~V}, M=0.7, f_{\mathrm{o}}=10 \mathrm{~Hz}$, $f_{\mathrm{sw}}=10 \mathrm{kHz}, T_{\mathrm{d}}=5 \mu \mathrm{s}, L=0.5 \mu \mathrm{H}, C=30 \mu \mathrm{F}$ and a resistive load $R=10 \Omega$,

When the inductor current is distinctly positive during deadtime, which is achieved in SSCCM and HSCCM, the magnitude of the inductor current change is expressed as

$$
\Delta i_{L, \mathrm{dp}}(n)=-\frac{V_{\mathrm{dc}} T_{\mathrm{d}}}{L}[1+m(n)] .
$$

Similarly, the magnitude of the inductor current change when the inductor current is distinctly negative during dead-time is described as

$$
\Delta i_{L, \mathrm{dn}}(n)=\frac{V_{\mathrm{dc}} T_{\mathrm{d}}}{L}[1-m(n)] .
$$

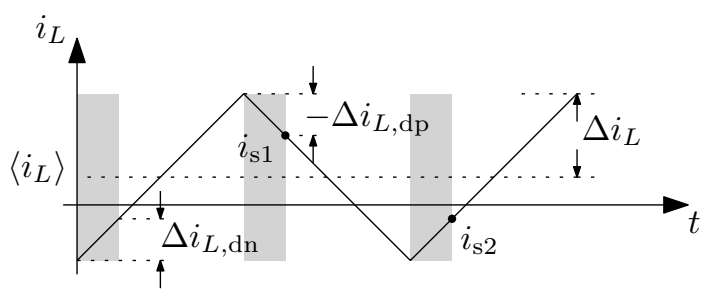

Fig. 5. The inductor current waveforms for SSCCM. The grey area represents for the dead-time.

The time position of different switching modes can be determined by the relation (7), (8), (9) and (10). The inductor current waveform for SSCCM is depicted in Fig. 5. In order to achieve soft-switching, there are constraints for $i_{\mathrm{s} 1}$ and $i_{\mathrm{s} 2}$, which are governed by

$$
\left\{\begin{array}{l}
i_{\mathrm{s} 1}(n)=\left\langle i_{L}(n)\right\rangle+\Delta i_{L}(n)+\Delta i_{L, \mathrm{dp}}(n) \geq 0 \\
i_{\mathrm{s} 2}(n)=\left\langle i_{L}(n)\right\rangle-\Delta i_{L}(n)+\Delta i_{L, \mathrm{dn}}(n) \leq 0
\end{array} .\right.
$$

The inductor current waveforms for DCM are depicted in Fig. 6. For the inductor waveform shown in Fig. 6(a), if the current loss during dead-time is neglected, the average value of the inductor current can be represented by

$$
\left\langle i_{L}(n)\right\rangle=i_{L, \mathrm{pk}}(n)-\Delta i_{L}(n),
$$

where $i_{L, \mathrm{pk}}(n)$ is the inductor peak current in each switching cycle. The constraints for $i_{\mathrm{da} 1}$ and $i_{\mathrm{ida} 2}$ are given by

$$
\left\{\begin{array}{l}
i_{\mathrm{da} 1}=\left\langle i_{L}(n)\right\rangle-\Delta i_{L}(n) \leq 0 \\
i_{\mathrm{da} 2}=\left\langle i_{L}(n)\right\rangle-\Delta i_{L}(n)+\Delta i_{L, \mathrm{dn}}(n)>0
\end{array} .\right.
$$

As a result, the clamping time $t_{\mathrm{c}}(n)$ yields

$$
t_{\mathrm{c}}(n)=\frac{\left\langle i_{L}(n)\right\rangle-\Delta i_{L}(n)+\Delta i_{L, \mathrm{dn}}(n)}{\Delta i_{L, \mathrm{dn}}(n)} T_{\mathrm{d}} .
$$

Therefore, the voltage error is found to be

$$
\left\langle u_{\mathrm{e}}(n)\right\rangle=\frac{\left(V_{\mathrm{dc}}-m(n) V_{\mathrm{dc}}\right) t_{\mathrm{c}}(n)}{T_{\mathrm{sw}}},
$$




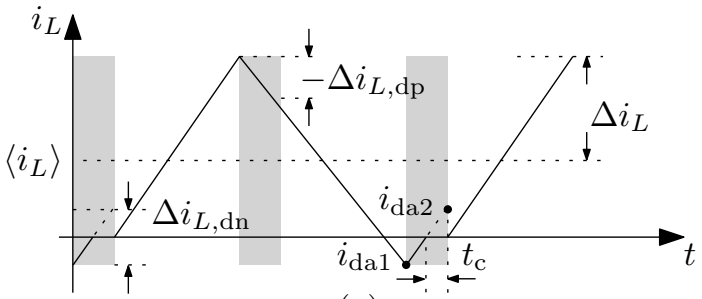

(a)

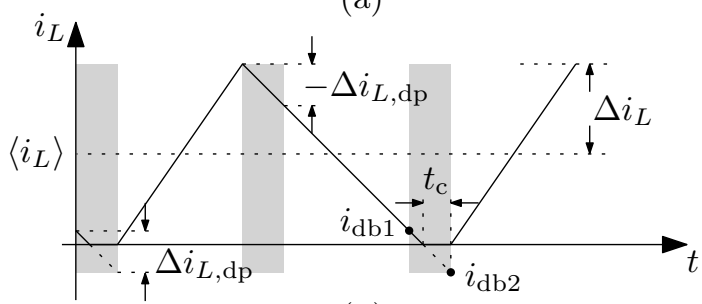

(b)

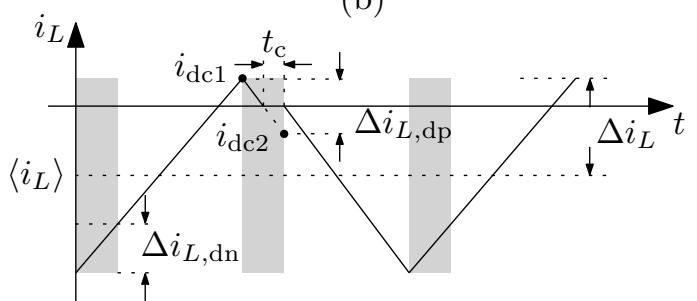

(c)

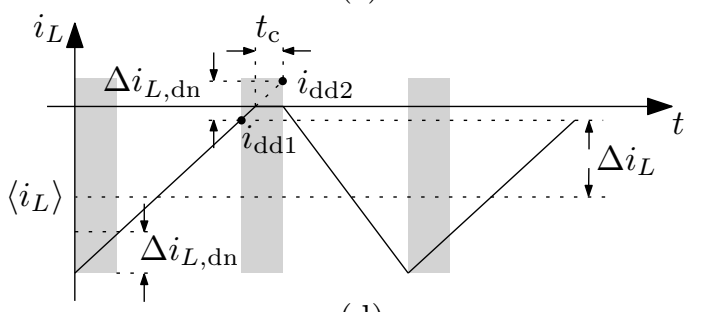

(d)

Fig. 6. The inductor current waveforms for DCM. (a) Inductor current rises from negative to zero and is clamped during dead-time with a positive average value in a switching cycle. (b) Inductor current falls from positive to zero and is clamped during dead-time with a positive average value in a switching cycle. (c) Inductor current falls from positive to zero and is clamped during dead-time with a negative average value in a switching cycle. (d) Inductor current rises from negative to zero and is clamped during dead-time with a negative average value in a switching cycle.

which can be rewritten as

$$
\left\langle u_{\mathrm{e}}(n)\right\rangle=\frac{L}{T_{\mathrm{sw}}}\left[\left\langle i_{L}(n)\right\rangle-\Delta i_{L}(n)+\Delta i_{L, \mathrm{dn}}(n)\right] .
$$

Similarly, the constraints for $i_{\mathrm{db} 1}$ and $i_{\mathrm{idb} 2}$ shown in Fig. 6 (b) are given by

$$
\left\{\begin{array}{l}
i_{\mathrm{db} 1}=\left\langle i_{L}(n)\right\rangle-\Delta i_{L}(n)>0 \\
i_{\mathrm{db} 2}=\left\langle i_{L}(n)\right\rangle-\Delta i_{L}(n)+\Delta i_{L, \mathrm{dp}}(n)<0 .
\end{array} .\right.
$$

The voltage error is calculated as

$$
\left\langle u_{\mathrm{e}}(n)\right\rangle=\frac{L}{T_{\mathrm{sw}}}\left[\left\langle i_{L}(n)\right\rangle-\Delta i_{L}(n)+\Delta i_{L, \mathrm{dn}}(n)\right],
$$

which shares the same value with Fig. 5(a). Consequently, the two DCM modes depicted in Fig. 6(a) and (b) with an

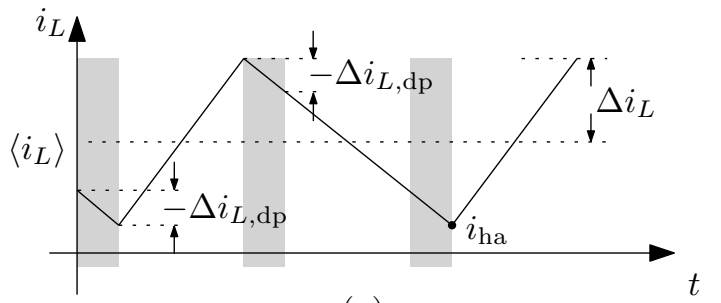

(a)

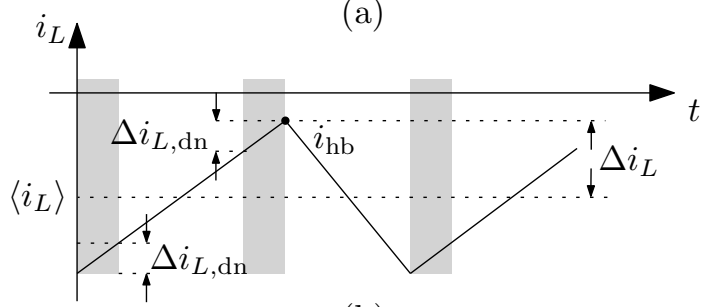

(b)

Fig. 7. The inductor current waveforms for HSCCM. (a) Distinctly positive inductor current. (b) Distinctly negative inductor current.

average positive inductor current can be combined. The current constraints are then expressed as

$$
\left\{\begin{array}{l}
\left\langle i_{L}(n)\right\rangle-\Delta i_{L}(n)+\Delta i_{L, \mathrm{dp}}(n)<0 \\
\left\langle i_{L}(n)\right\rangle-\Delta i_{L}(n)+\Delta i_{L, \mathrm{dn}}(n)>0 .
\end{array}\right.
$$

By the same token, the current constraints and voltage error for the DCM with negative average inductor currents depicted in Fig. 6(c) and (d) are described by

$$
\left\{\begin{array}{l}
\left\langle i_{L}(n)\right\rangle+\Delta i_{L}(n)+\Delta i_{L, \mathrm{dp}}(n)<0 \\
\left\langle i_{L}(n)\right\rangle+\Delta i_{L}(n)+\Delta i_{L, \mathrm{dn}}(n)>0
\end{array}\right.
$$

and

$$
\left\langle u_{\mathrm{e}}(n)\right\rangle=\frac{L}{T_{\mathrm{sw}}}\left[\left\langle i_{L}(n)\right\rangle+\Delta i_{L}(n)+\Delta i_{L, \mathrm{dp}}(n)\right]
$$

respectively. The inductor current waveform for HSCCM are shown in Fig. 7. It can be easily derived that the current constraint and the voltage error for SSCCM depicted in Fig. 7(a) and (b) are given by

$$
\begin{aligned}
& i_{\mathrm{hb}}(n)=\left\langle i_{L}(n)\right\rangle-\Delta i_{L}(n)+\Delta i_{L, \mathrm{dp}}(n)>0, \\
& i_{\mathrm{hb}}(n)=\left\langle i_{L}(n)\right\rangle+\Delta i_{L}(n)+\Delta i_{L, \mathrm{dn}}(n)<0
\end{aligned}
$$

and

$$
\begin{gathered}
\left\langle u_{\mathrm{e}}(n)\right\rangle=\frac{2 V_{\mathrm{dc}} T_{\mathrm{d}}}{T_{\mathrm{sw}}}, \\
\left\langle u_{\mathrm{e}}(n)\right\rangle=-\frac{2 V_{\mathrm{dc}} T_{\mathrm{d}}}{T_{\mathrm{sw}}}
\end{gathered}
$$

respectively. Therefore, the time position of different switching modes can be determined by four current constraint functions $y_{\mathrm{sp}}(n), y_{\mathrm{sn}}(n), y_{\mathrm{cp}}(n)$ and $y_{\mathrm{cn}}(n)$, which are defined by

$$
\begin{aligned}
& y_{\mathrm{sp}}(n)=\left\langle i_{L}(n)\right\rangle+\Delta i_{L}(n)+\Delta i_{L, \mathrm{dp}}(n), \\
& y_{\mathrm{sn}}(n)=\left\langle i_{L}(n)\right\rangle-\Delta i_{L}(n)+\Delta i_{L, \mathrm{dn}}(n), \\
& y_{\mathrm{cp}}(n)=\left\langle i_{L}(n)\right\rangle+\Delta i_{L}(n)+\Delta i_{L, \mathrm{dn}}(n)
\end{aligned}
$$




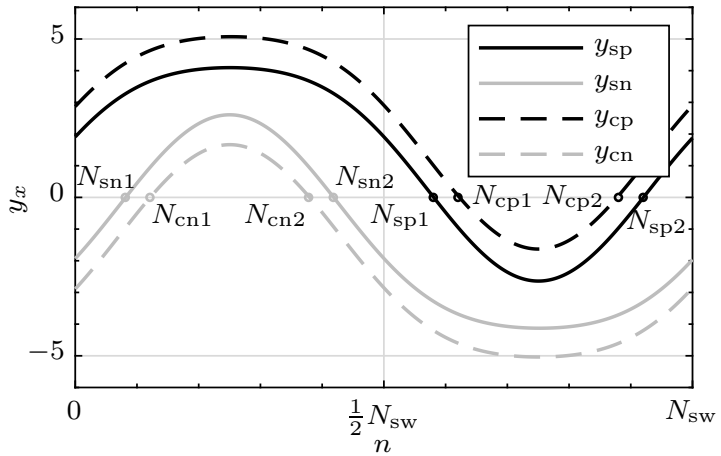

Fig. 8. The current constraints of the different switching modes.

and

$$
y_{\mathrm{cn}}(n)=\left\langle i_{L}(n)\right\rangle-\Delta i_{L}(n)+\Delta i_{L, \mathrm{dp}}(n)
$$

respectively. Thereby the current constraint functions can be used to describe the three kinds of switching modes. The current constraints of SSCCM cycle are given by

$$
\left\{\begin{array}{l}
y_{\mathrm{sp}}(n) \geq 0 \\
y_{\mathrm{sn}}(n) \leq 0
\end{array}\right.
$$

The current constraints of DCM cycle are described by

$$
\left\{\begin{array}{l}
y_{\mathrm{cn}}(n)<0 \\
y_{\mathrm{sn}}(n)>0
\end{array}\right.
$$

or

$$
\left\{\begin{array}{l}
y_{\mathrm{cp}}(n)>0 \\
y_{\mathrm{sp}}(n)<0
\end{array}\right.
$$

The current constraints of the HSCCM cycle are governed by

$$
y_{\mathrm{cp}}(n) \leq 0
$$

or

$$
y_{\text {cn }}(n) \geq 0 .
$$

As a result, by solving the equations $y_{\mathrm{sp}}(n)=0, y_{\mathrm{sn}}(n)=0$, $y_{\mathrm{cp}}(n)=0$ and $y_{\mathrm{cn}}(n)=0$, the time positions of the different switching modes can be determined. All the constraint functions are periodic with a period of $N_{\mathrm{sw}}$. Fig. 8 shows one possibility for the constraint functions. It should be noted that none of the constraint functions have certainly two intersections with the $\mathrm{x}$-axis. For example, if $y_{\mathrm{sp}}(n)$ and $y_{\mathrm{sn}}(n)$ have no intersection with $\mathrm{x}$-axis in a whole output period, then soft-switching is achieved all the time and there is no DCM or HSCCM switching cycle. Similarly, if $y_{\mathrm{cp}}(n)$ and $y_{\mathrm{cn}}(n)$ have no intersection with $\mathrm{x}$-axis in a whole output period, then there are only SSCCM and DCM but no HSCCM switching cycle. The HSCCM cycle exists if and only if all the constraint functions have intersections with $\mathrm{x}$-axis, which is the most typical case and is the main focus in this paper.

The intersections of all the constraint functions with axis are denoted by $N_{\mathrm{sp} 1}$ and $N_{\mathrm{sp} 2}, N_{\mathrm{sn} 1}$ and $N_{\mathrm{sn} 2}, N_{\mathrm{cp} 1}$ and $N_{\mathrm{cp} 2}$ and $N_{\mathrm{cn} 1}$ and $N_{\mathrm{cn} 2}$ respectively as shown in Fig. 8. Therefore,
SSCCM cycles happen in time interval $\left[0, N_{\mathrm{sn} 1}\right],\left[N_{\mathrm{sn} 2}, N_{\mathrm{sp} 1}\right]$ and $\left[N_{\mathrm{sp} 2}, N_{\mathrm{sw}}-1\right]$, where voltage error is zero. DCM cycles happen in time interval $\left(N_{\mathrm{sn} 1}, N_{\mathrm{cn} 1}\right),\left(N_{\mathrm{cn} 2}, N_{\mathrm{sn} 2}\right)$, $\left(N_{\mathrm{sp} 1}, N_{\mathrm{cp} 1}\right)$ and $\left(N_{\mathrm{cp} 2}, N_{\mathrm{sp} 2}\right)$. HSCCM cycles happen in time interval $\left[N_{\mathrm{cn} 1}, N_{\mathrm{cn} 2}\right]$ and $\left[N_{\mathrm{cp} 1}, N_{\mathrm{cp} 2}\right]$.

The voltage error in a full fundamental period can be described by

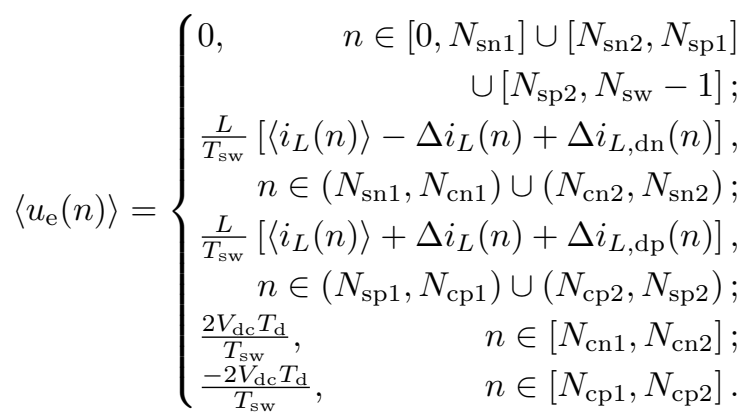

\section{Output spectrum analysis}

Based on the analysis of the three kinds of switching modes, both analytical and numerical methods can be adopted to calculate the output spectrum of the H-bridge inverter with SPWM. The analytical methods are based on the assumption that there are only HSCCM cycles in a full fundamental period, which are introduced in [6], [12] and [13]. Therefore, the voltage error is then expressed as

$$
u_{\mathrm{e}}(t)=\frac{2 V_{\mathrm{dc}} T_{\mathrm{d}}}{T_{\mathrm{sw}}} \operatorname{sign}\left(\sin \left(2 \pi f_{\mathrm{o}} t-\varphi_{\mathrm{o}}\right)\right),
$$

where $\operatorname{sign}(\cdot)$ extracts the sign of the content. By using the Fourier series (FS) expansion, the voltage error can be represented as

$$
u_{\mathrm{e}}(t)=\sum_{k=1}^{\infty}\left[\frac{-1+(-1)^{k}}{2}\right] \frac{8}{k \pi} \frac{V_{\mathrm{dc}} T_{\mathrm{d}}}{T_{\mathrm{sw}}} \sin \left(2 \pi f_{\mathrm{o}} t-\varphi_{\mathrm{o}}\right),
$$

where $k$ is the harmonic order. Therefore, the output voltage is calculated by $u_{\text {out }}(t)=u_{\text {ref }}-u_{\mathrm{e}}(t)$. The amplitude of the each harmonic is found to be

$A_{k}=\left\{\begin{array}{lr}\sqrt{\left(M V_{\mathrm{dc}}\right)^{2}+\left(\frac{8 V_{\mathrm{dc}} T_{\mathrm{d}}}{T_{\mathrm{sw}}}\right)^{2}-\frac{8 M V_{\mathrm{dc}}^{2} T_{\mathrm{d}}}{\pi T_{\mathrm{sw}}} \cos \left(\varphi_{\mathrm{o}}\right)}, k=1 ; \\ \frac{8}{k \pi} \frac{V_{\mathrm{dc}} T_{\mathrm{d}}}{T_{\mathrm{sw}}}, & k \text { is odd and } k \neq 1 ; \\ 0, & k \text { is even. }\end{array}\right.$

The analytical method yields a result that there are no even harmonics. Besides, the odd harmonics monotonically decrease with the increasing harmonic order, which is not always correct in practice. The deviation is resulted from neglecting the SSCCM and DCM switching cycles. Therefore, a more accurate method can be used to calculate the output spectrum based on (35). Since the time position of the switching cycles cannot be calculated by an analytical expression, this new method is numerical.

A lot of numerical methods can be used to calculate the roots of the non-linear equations, such as Newton's Method, Broyden's Method and Secant Methods [16]. This paper 


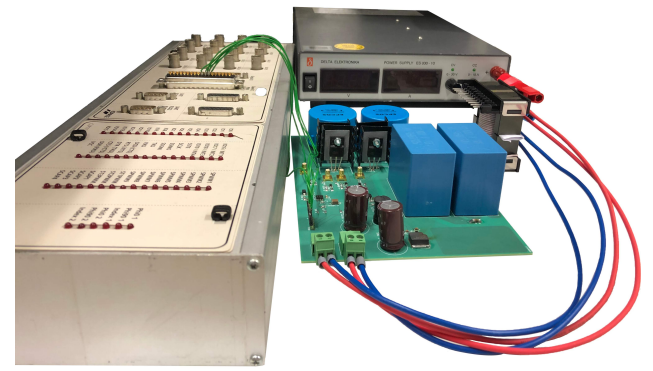

Fig. 9. The experimental setup for distortion measurement. From left to right: dSPACE DS1104 Controller Board, an H-bridge inverter prototype and a power supply.

focuses on the calculation of the output spectrum and the process of calculating the time position is omitted. The voltage error is a discrete periodic signal with a period of $N_{\mathrm{sw}}$, thus discrete-time Fourier series (DTFS) can be used to analyse the harmonic components of the voltage error, as described by

$$
c_{k}=\frac{1}{N_{\mathrm{sw}}} \sum_{n=0}^{N_{\mathrm{sw}}-1}\left\langle u_{\mathrm{e}}(n)\right\rangle e^{-j 2 \pi k n / N_{\mathrm{sw}}}
$$

where $c_{k}$ is the coefficient of the corresponding harmonic. Since $\left\langle u_{\mathrm{e}}(n)\right\rangle$ is a real signal, $c_{k}$ and $c_{-k}$ are conjugated [17]. As a result, the voltage error can also be rewritten as

$$
\left\langle u_{\mathrm{e}}(n)\right\rangle=\left\{\begin{array}{c}
\frac{1}{N_{\mathrm{sw}}} \sum_{n=0}^{N_{\mathrm{sw}}-1}\left\langle u_{\mathrm{e}}(n)\right\rangle, \quad k=0 ; \\
a_{k} \cos \left(\frac{2 \pi k n}{N_{\mathrm{sw}}}\right)+b_{k} \sin \left(\frac{2 \pi k n}{N_{\mathrm{sw}}}\right), \\
k=1,2, \cdots, N_{\mathrm{sw}} / 2-1 ; \\
\text { irrelavant, } \quad k>N_{\mathrm{sw}} / 2-1,
\end{array}\right.
$$

where $a_{k}=c_{k}+c_{-k}$ and $b_{k}=j\left(c_{k}-c_{-k}\right)$. As a result, the output voltage is given by $u_{\text {out }}(n)=V_{\mathrm{dc}} m(n)-\left\langle u_{\mathrm{e}}(n)\right\rangle$ and the magnitude of each harmonic of the output voltage $A_{k}$ is given by [18]

$$
A_{k}= \begin{cases}\frac{1}{N_{\mathrm{sw}}} \sum_{n=0}^{N_{\mathrm{sw}}-1}\left\langle u_{\mathrm{e}}(n)\right\rangle, & k=0 ; \\ \sqrt{\left(M V_{\mathrm{dc}}-b_{k}\right)^{2}+\left(-a_{k}\right)^{2}}, & k=1 ; \\ \sqrt{\left(a_{k}^{2}+b_{k}^{2}\right)}, k=2,3, \cdots, N_{\mathrm{sw}} / 2-1 .\end{cases}
$$

The magnitude of the odd harmonic derived from the numerical method is not always monotonically decreasing. The magnitude of the even harmonic is also zero theoretically but it yields nonzero values due to the rounding error of switching cycle calculation. The relative magnitude of each harmonic $R_{k}$ is defined by

$$
R_{k}=20 \log _{10} \frac{A_{k}}{A_{1}} .
$$

\section{Simulation AND EXPERIMENT RESULTS}

Both simulations and experiments are done to verify the presented method. The simulations are done using MATLAB/Simulink while the experiments are conducted on a setup using dSPACE with a SPWM H-bridge inverter, as shown in Fig. 9. The harmonics are measured by an SR785

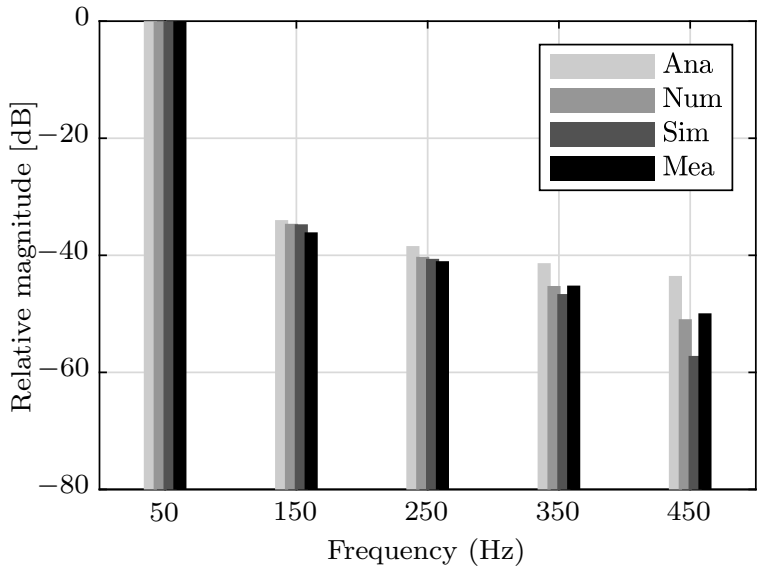

Fig. 10. The output voltage spectrum for $M=0.9, f_{\mathrm{o}}=50 \mathrm{~Hz}, f_{\mathrm{sw}}=$ $10 \mathrm{kHz}$ and $L=2 \mu \mathrm{H}$.

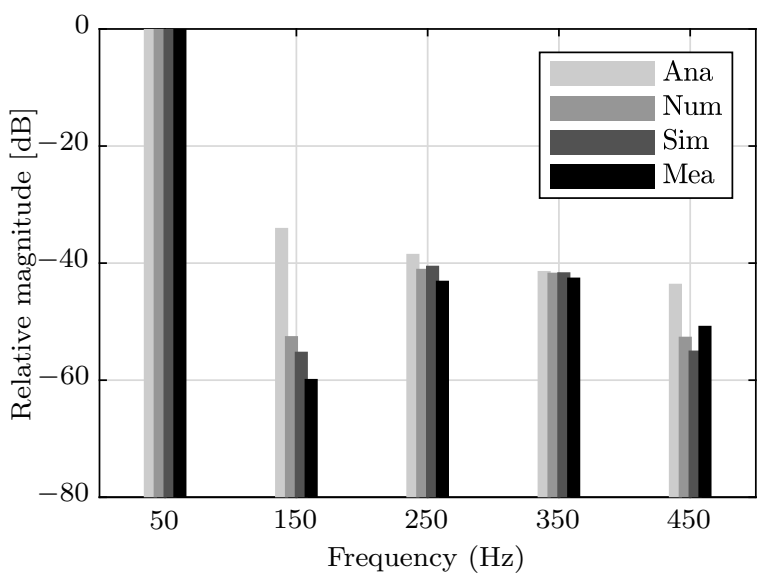

Fig. 11. The output voltage spectrum for $M=0.9, f_{\mathrm{o}}=50 \mathrm{~Hz}, f_{\mathrm{sw}}=$ $10 \mathrm{kHz}$ and $L=0.5 \mu \mathrm{H}$.

signal analyser. The relative magnitude of the output voltage harmonics is used for comparison in order to suppress the effect of the on-resistance of the MOSFETs and the series resistance of the filter inductor. The time positions of SSCCM and DCM are highly influenced by the inductor current ripple, which is determined by the filter inductance. Thereby two different filter inductors are used to investigate the effect of SSCCM and DCM for a fixed dead-time of $T_{\mathrm{d}}=2 \mu \mathrm{s}$ under $V_{\mathrm{dc}}=48 \mathrm{~V}$. The filter capacitor is selected as $C=30 \mu \mathrm{F}$. A resistor $R=10 \Omega$ is used as a load. The output spectrum are depicted in Fig. 10 and Fig. 11, where Ana, Num, Sim and Mea represent for the results of the analytical method, the presented numerical method, the simulation and the measurement respectively. The absolute errors of different methods compared to the measurements are listed in Table I and Table II. The SPWM distortion is neglected in calculations. The even harmonics are skipped in the plots.

When $L=2 \mu \mathrm{H}$, the maximum current ripple is as low as a factor of $12.5 \%$ of the output current and the effect of SSCCM 
TABLE I

THE HARMONIC ERRORS OF DIFFERENT METHODS COMPARED TO THE MEASUREMENTS FOR $L=2 \mu \mathrm{H}$

\begin{tabular}{ccccc}
\hline \multirow{2}{*}{ Methods } & \multicolumn{4}{c}{ Absolute errors of harmonic components $(\mathrm{dB})$} \\
\cline { 2 - 5 } & 3rd & 5 th & 7 th & 9 th \\
\hline Analytical & 2.09 & 2.58 & 3.83 & 6.38 \\
Numerical & 1.46 & 0.75 & 0.07 & 1.01 \\
Simulation & 1.37 & 0.40 & 1.44 & 7.28 \\
\hline
\end{tabular}

TABLE II

THE HARMONIC ERRORS OF DIFFERENT METHODS COMPARED TO THE MEASUREMENTS FOR $L=0.5 \mu \mathrm{H}$

\begin{tabular}{lcccc}
\hline \multirow{2}{*}{ Methods } & \multicolumn{4}{c}{ Absolute errors of harmonic components $(\mathrm{dB})$} \\
\cline { 2 - 5 } & 3rd & 5 th & 7 th & 9 th \\
\hline Analytical & 25.8 & 4.59 & 1.13 & 7.19 \\
Numerical & 7.31 & 2.03 & 0.83 & 1.86 \\
Simulation & 4.65 & 2.56 & 0.91 & 4.23 \\
\hline
\end{tabular}

and DCM switching cycles is relatively small. In this case, the odd harmonic is decreasing in magnitude with the growth of the harmonic order. Analytical and numerical methods give the similar estimation result of the odd harmonics. However, the presented numerical method has a better accuracy compared to the analytical method, especially for the estimation of the seventh and ninth harmonics, as shown in Table I. Generally, the accuracy is better than simulation since the accuracy of the simulation is highly dependent on the step size and solver.

When $L=0.5 \mu \mathrm{H}$, the maximum current ripple is $50 \%$ of the output current and the effect of SSCCM and DCM switching cycles becomes more obvious on the output spectrum. The measured third harmonic is $16 \mathrm{~dB}$ lower than fifth harmonic, which goes against the analytical method but accords with the numerical method. The numerical method gives a much more accurate result than the analytical method, especially for the third harmonic, which is $17.5 \mathrm{~dB}$ closer to the measured value, as shown in Table II. Compared to the measurement result for $L=2 \mu \mathrm{H}$, the magnitude of the third harmonic is reduced by $23.7 \mathrm{~dB}$ due to the effect of SSCCM and DCM.

\section{CONCLUSiON}

This paper demonstrates the characteristics and the effects of the different switching modes, including SSCCM, DCM and HSCCM in an H-bridge inverter. Natural sampling SPWM and bipolar modulation are used for an example while the method can be applied to other sampling and modulation methods as well. The voltage errors of the three types of switching modes in all switching cycles are analysed and calculated. The current constraint functions are introduced and used to determine the time position of different switching modes numerically. A numerical method is then addressed to calculate the output spectrum of H-bridge inverter by taking the effects of SSCCM, DCM and HSCCM into consideration. It is shown that SSCCM and DCM can reduce harmonics.
The presented numerical method yields a better accuracy than the analytical one, especially when the inductor current ripple is large. In general, when the inductor current ripple is low, the analytical and numerical method give similar results in estimating the odd harmonics while the analytical method is simpler. When the inductor current ripple is high, the numerical method has a significant improvement of accuracy at the cost of more computational effort. Moreover, the numerical method saves a lot of computational cost compared to simulation. The method can be used for feed-forward deadtime compensation. The further research can be focus on the sensitivity of the inductance and load impedance variation.

\section{REFERENCES}

[1] J. M. Schellekens, J. L. Duarte, H. Huisman, and M. A. M. Hendrix, "Elimination of zero-crossing distortion for high-precision amplifiers," IECON Proc. (Industrial Electron. Conf., pp. 3370-3375, 2011.

[2] Q. Yu, R. Baeten, E. Lemmen, B. Vermulst, and K. Wijnands, "A 1 $\mathrm{MHz}$ Wide Bandgap Power Amplifier for High-Precision Applications," in 2019 21st Eur. Conf. Power Electron. Appl.

[3] I. Dolguntseva, "Application of Fourier Series Expansion to Electrical Power Conversion," in Fourier Transform. - High-tech Appl. Curr. Trends. InTech, feb 2017.

[4] E. Lee, S. Huang, J. Huang, and S. Chung, "Applications of describing functions to estimate the performance of nonlinear inductance," IEE Proc. - Sci. Meas. Technol., vol. 148, no. 3, pp. 108-114, 2002.

[5] Y. Zhang, R. Zane, A. Prodic, R. Erickson, and D. Maksimovic, "Online calibration of MOSFET on-state resistance for precise current sensing," IEEE Power Electron. Lett., vol. 2, no. 3, pp. 100-103, 2004.

[6] F. Chierchie and E. Paolini, "Analytical and numerical analysis of dead-time distortion in power inverters," Argentine Sch. MicroNanoelectronics Technol. Appl. (EAMTA), 2010, pp. 6-11, 2010.

[7] S. K. Dunlap and T. S. Fiez, "A noise-shaped switching power supply using a delta-sigma modulator," IEEE Trans. Circuits Syst. I Regul. Pap., vol. 51, no. 6, pp. 1051-1061, 2004.

[8] B. J. D. Vermulst, "Compensating Baseband Distortion of Regularly Sampled Pulsewidth Modulators for High-Precision Power Converters," IEEE Trans. Power Electron., vol. 34, no. 7, pp. 6257-6263, jul 2019.

[9] S. Y. Kim, W. Lee, M. S. Rho, and S. Y. Park, "Effective dead-time compensation using a simple vectorial disturbance estimator in PMSM drives," IEEE Trans. Ind. Electron., vol. 57, no. 5, pp. 1609-1614, 2010.

[10] C. Attaianese, V. Nardi, and G. Tomasso, "A novel SVM strategy for VSI dead-time-effect reduction," IEEE Trans. Ind. Appl., vol. 41, no. 6, pp. 1667-1674, 2005

[11] Yong-Kai Lin and Yen-Shin Lai, "Dead-Time Elimination of PWMControlled Inverter/Converter Without Separate Power Sources for Current Polarity Detection Circuit," IEEE Trans. Ind. Electron., vol. 56, no. 6, pp. 2121-2127, 2009.

[12] C. Wu, W. H. Lau, and H. S. H. Chung, "Analytical technique for calculating the output harmonics of an H-bridge inverter with dead time," IEEE Trans. Circuits Syst. I Fundam. Theory Appl., vol. 46, no. 5, pp. 617-627, 1999.

[13] D. C. Moore, M. Odavic, and S. M. Cox, "Dead-time effects on the voltage spectrum of a PWM inverter," IMA J. Appl. Math., vol. 79, no. 6, pp. 1061-1076, 2014.

[14] J. M. Schellekens, R. A. M. Bierbooms, and J. L. Duarte, "Deadtime compensation for PWM amplifiers using simple feed-forward techniques," 19th Int. Conf. Electr. Mach. ICEM 2010, pp. 1-6, 2010.

[15] E. Lemmen, J. M. Schellekens, C. G. E. Wijnands, and J. L. Duarte, "Advances in High-Precision Amplifiers - The Extra L Opposed Current Converter," IEEE Trans. Power Electron., vol. 30, no. 10, pp. 5691$5700,2015$.

[16] J. E. Dennis and R. B. Schnabel, Numerical Methods for Unconstrained Optimization and Nonlinear Equations. Society for Industrial and Applied Mathematics, jan 1996.

[17] S. B. Weinstein and P. M. Ebert, "Data Transmission by FrequencyDivision Multiplexing Using the Discrete Fourier Transform," IEEE Trans. Commun. Technol., vol. 19, no. 5, pp. 628-634, 1971.

[18] L. Marple, "Computing the discrete-time "analytic" signal via FFT," IEEE Trans. Signal Process., vol. 47, no. 9, pp. 2600-2603, 1999. 